\title{
Tentative Age-related Norms for High Frequency Electric Bone Conduction Audiometry
}

\author{
G R Voogt \\ Department of Otorhinolaryngology \\ Medical University of Southern Africa \\ H S Schoeman \\ Department of Mathematics and Statistics \\ Medical University of Southern Africa
}

\begin{abstract}
From 172 male and female patients aged 7-71 years old and admitted in one month to a tuberculosis hospital, 150 had their highest audible electric bone conduction (EBC) frequency evaluated, prior to the commencement of any medical treatment. Various problems in establishing high frequency norms are discussed and from the results of this study tentative agerelated highest frequency $E B C$ norms are suggested. Possible clinical applications of evaluating the highest audible EBC frequency is suggested.
\end{abstract}

\section{OPSOMMING}

Van 172 manlike en vroulike pasiënte met ouderdomme 7-71 jaar oud wat in een maand opgeneem is in ' $n$ tuberkulosehospitaal, is 150 se hoogste hoorbare elektriese beengeleidingsfrekwensie bepaal, voor die aanvang van enige mediese behandeling. Verskeie probleme in die daarstelling van hoëfrekwensie-norme word bespreek en uit die resultate van hierdie studie word tentatiewe ouderdomsverwante hoogste hoorbare elektriese beengeleidingsfrekwensienorme voorgestel. Moontlike kliniese toepassings van die bepaling van die hoogste hoorbare elektriese beengeleidingsfrekwensie word voorgestel.

KEY WORDS: highest audibile frequency, electric bone conduction, age, sex, norms.

\section{INTRODUCTION}

As early as 1876 Galton showed interest in establishing the upper frequency hearing limits for humans, by using such crude instrumentation as whistles in his examinations (Galton, 1876).

The interest in compiling high frequency normative data dates way back to 1929 , when Dr. Harvey Fletcher's original reports on high frequency normative studies were published. At that time he reported that the data was very uncertain and varied greatly amongst individuals (Fletcher, 1929).

Since those early years immense progress has been made in design and development of audiometers, testing procedures and calibration of the equipment. However, different researchers still reported widely differing data for high frequency hearing thresholds and thus also normative data (Sivian \& White, 1933; Dadson \& King, 1952; Rudmose, 1961; Zislis \& Fletcher, 1966; Harris \& Myers, 1971; and Northern, Downs, Rudmose, Glorig \& Fletcher, 1972). Thus reports on high frequency audiometry originated from research investigations but no clinical applications were suggested.
Recently many investigators have shown renewed interest in high frequency audiometry as more and more possible clinical applications have become evident. Jacobson, Downs and Fletcher (1969) applied high frequency audiometry for the early detection of ototoxicity; Corliss, Doster, Simonton and Downs (1970) for detecting noise-induced hearing damage; Fletcher, Cairns, Collins and Endicott (1967) for detecting hearing loss due to meningitis; Rosen and Olin (1968) for detecting hearing loss related to coronary heart disease. In all cases only air conduction stimulation was used.

As no normative threshold data existed, much use was made of baseline threshold data to which any changes in hearing, subsequent to diseases or treatment, was compared. Methods of testing, instrumentation and calibration of instrumentation also differed widely (Northern et al., 1972).

Until 1988 high frequency audiometry was mostly restricted to studies involving sensori-neural disease processes, thus the interpretation of high frequency threshold changes have remained largely conjectural. Bone conduction audiometry has been restricted to the frequency range of $250 \mathrm{~Hz}$ to $6 \mathrm{KHz}$, because bone vibrator quality is poor 
at higher frequencies. This latter problem was largely overcome in 1984 by the development of the "electric boneconduction" audiometer which works by electro-stimulation via mylar coated electrodes on the skin over the mastoid (Tonndorf \& Kurman, 1984), which has excellent testretest reliability (Okstad, Laukli \& Mair, 1988) and can test up to $20 \mathrm{KHz}$.

Despite all these developments, various factors still prevent the establishment of proven, reliable high frequency normative threshold data. Consider that to calibrate a standard air conduction audiometer a $6 \mathrm{~cm}^{3}$ IEC 303 coupler has to be used and the audiometer output calibrated to ISO 389 (1985) standards. To calibrate an air conduction audiometer which can test up to $20 \mathrm{KHz}$, eg., the Demlar $20 \mathrm{~K}$, a special coupler supplied by the manufacturer of this audiometer should be used. When an "electric bone-conduction" audiometer, eg., the Audimax 500 has to be calibrated, the electric output must be connected to a simulated load supplied by the manufacturer of the Audimax. Thus there appears to be no hard and fast standard of calibration for these very different types of audiometers.

In evaluation of clinical testing, further problems re use of high frequency audiometry surfaced. When comparing hearing thresholds on the same subjects using a Demlar 20K and an Audimax 500, Okstad et al. (1988) found that this does not result in equivalent air conduction and bone conduction thresholds at all frequencies. Schechter, Fausti, Rappaport and Frey (1986) found that factors such as age, gender, different equipment, different testing procedures, headphone placement, ear canal acoustics, etc., all interact to give a great degree of intersubject variability in the high frequency hearing range.

Tonndorf and Kurman (1984) and Okstad et al. (1988) found that the normative electric bone conduction (EBC) threshold curves are relatively flat up to a variable cut-off frequency, after which there is a very sharp fall of thresholds over the subsequent 2 or $3 \mathrm{KHz}$. This sharp fall indicates the point of highest audible frequency at hearing threshold level. However, it still does not indicate the real highest frequency at which the subject may be able to hear at higher stimulus intensities.

Furthermore, in audiometric testing the stimulus intensity scale is logarithmic, while in EBC testing it is linear. Consider further that the conventional frequency scale is also logarithmic, while in EBC testing it is linear. Therefore it would appear that by keeping the stimulus intensity constant and at the maximum of the audiometer, while measuring the highest audible frequency, it would lead to a more finely determined and therefore more accurate test result.

Recently a considerable amount of research was done on high frequency hearing and thresholds. Frank (1990) examined high frequency air conduction thresholds in adults 18-28 years old; Frank and Dreisbach (1991) tested for repeatability of high frequency air conduction thresholds in adults 19-27 years old; Schechter et al. (1986) and Stelmachowicz, Beauchaine, Kalberer and Jesteadt (1989) worked on age-related high frequency air conduction thresholds; Okstad et al. (1988) compared high frequency air conduction and bone conduction thresholds in adults 20-24 years old. The differences in testing equipment, methodology and subjects result in considerable difficulties when attempting direct comparison of their results. There was found to be reasonable agreement on high frequency air conduction thresholds and norms, but not much on high frequency bone conduction.
In an effort to try to establish some kind of high frequency EBC hearing norms, utilizing the suggested method of measuring the highest audible EBC frequency, a group of subjects of differing age and sex were tested at the maximum stimulus intensity of the EBC audiometer. The results may possibly then also shed more light on the pattern of loss of high frequency bone conduction hearing with increasing age and the possible effects that gender may have on this pattern.

\section{METHODOLOGY}

All 172 patients admitted over a period of one month to a tuberculosis hospital, whether for treatment or followup examinations, (and statistically not a representative sample of the population) had their highest audible frequency evaluated at the maximum stimulus intensity of the audiometer (120 Electro-Stimulation Units which compares to about $60 \mathrm{~dB}$ SPL).

The audiometer used was an Audimax 500, which essentially measures EBC hearing up to $20 \mathrm{KHz}$. The highest audible EBC frequency was determined by increasing and decreasing the stimulus frequency in $100 \mathrm{~Hz}$ steps. The point of highest audible EBC frequency was defined as that level at which the subject indicated he could just barely detect the sound, this level being crossed in three runs consecutively. As no effective masking is available, the test results indicated the hearing binaurally. The hospital is built on a vast expanse of open field, resulting in very quiet surroundings. The hearing tests were performed in a large and unused dental examination room which is situated a considerable distance away from the main hospital buildings, resulting in an extremely quiet test environment.

The subjects included different indigenous races, male and female, with age ranging from 7 to 71 yrs old. From these subjects, 22 had to be excluded because they displayed poor hearing/no hearing in the $8-20 \mathrm{KHz}$ range, had middle ear problems (determined by standard audiometry and impedance tests), were previously treated with ototoxic drugs or had previous exposure to occupational industrial noise (determined by examining case histories and questioning subjects).

The subjects were grouped into ten year age intervals, mainly to be able to compare the results with those from other researchers at a later stage. Each subject was tested twice, on consecutive days, in order to make sure, that the test results had test-retest repeatability, differences not exceeding $200 \mathrm{~Hz}$. The average of the two measurements on each subject was then considered as the highest audible EBC frequency. These test results were then cross referenced with age and gender.

\section{RESULTS}

Figure 1 shows a plotting of the mean values of the highest audible EBC frequencies, calculated from the raw data, for males, females, and males and females together, set out in ten year age groups. Although males showed slightly higher mean values than females for all age groups, (see Fig. 1) this difference between the two sexes was not statistically significant. Consequently, the data for males and females were lumped together.

Statistical data from the test results for males and females together are displayed in Table 1. 
From Table 1 a definite but gradual decrease is observed in mean highest audible EBC frequency with increasing age. The youngest age group constituted one subject only, who could hear right up to $18,4 \mathrm{KHz}$. This is followed by a reduction through the older age groups down to $11,15 \mathrm{KHz}$ in the second last group. The last (oldest) group constituted only one subject aged 71 years old. This subject showed a repeatable highest audible $\mathrm{EBC}$ frequency of 16,4 $\mathrm{KHz}$.

Figure 2 shows the mean, standard deviation and range of highest audible EBC frequency, set out in ten year age groups, for all the subjects together, except for the youngest and oldest age groups which were excluded because of one subject only in each of these two age groups.

\section{DISCUSSION}

From the results of this study it would appear that the highest audible EBC frequency decreases linearly with increasing age. This decrease cannot be ascribed to being infected by Mycobacterium tuberculosis or to being previously treated with any of the four standard antituberculosis drugs (rifampicin, isoniazid, pyrazinamide and ethambutol) as neither has any effect on hearing (Teale,
Goldman \& Pearson, 1994). If it is assumed that this is a result of sensory presbycusis due to hair cell loss in the basal cochlea (Schuknecht, 1955), then it would appear that presbycusis possibly starts at a very early age and follows a distinct linear pattern of reduction in highest frequency hearing with increasing age. This phenomenon appears to affect males and females of all age groups in exactly the same way, as no statistically different gender discrepancies could be established. This differs from the findings of Stelmachowicz et al. (1989) who found a small but statistically significant difference, males showing a $4,4 \mathrm{~dB}$ poorer threshold. This may be ascribed to differences in type of auditory stimulation (air conduction vs. bone conduction) used in these two studies. The finding of a gradual decrease in highest audible frequency with increasing age is in agreement with the finding of Stelmachowicz et al. (1989) of a monotonical increase in high frequency threshold as a function of age.

As a direct result of this linear pattern it would be a fairly easy matter to establish age-related norms for highest frequency $\mathrm{EBC}$ hearing. A complicating factor was the wide variation in highest audible frequency within each age group, which resulted in the normative curve being quite wide on both sides of the mean threshold line, as

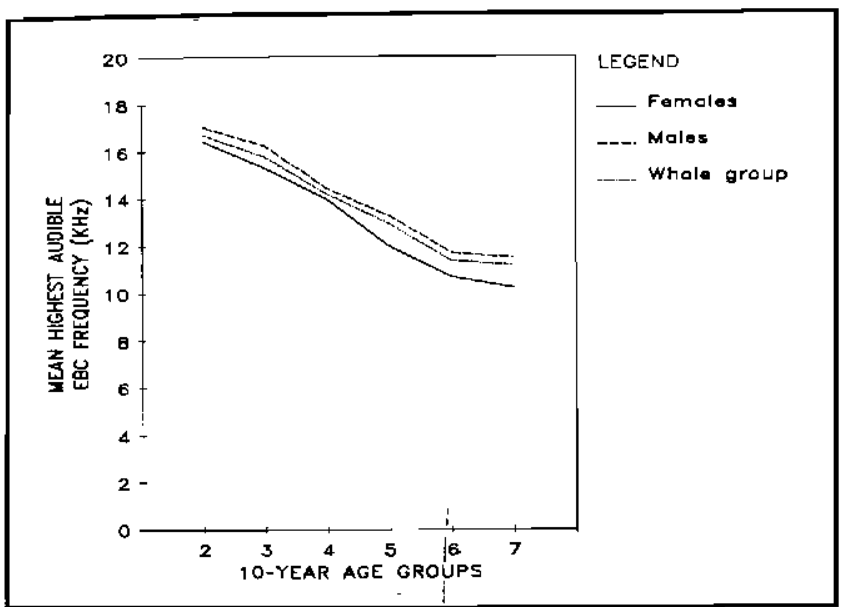

FIGURE 1: Mean values of highest audible EBG frequencies.

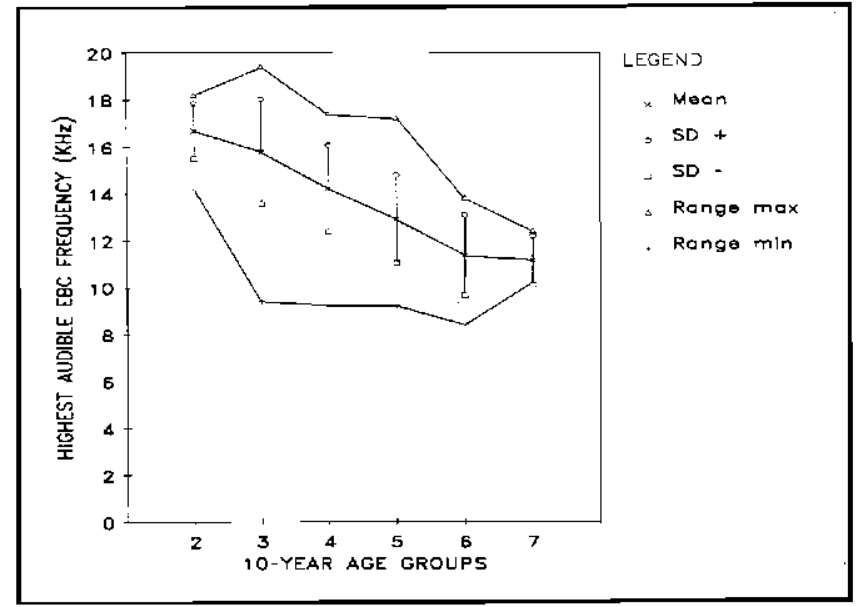

FIGURE 2: Mean, stand. dev. and range of highest audible EBC.

TABLE 1: Statistical data by Age Group.

\begin{tabular}{|c|c|c|c|c|c|c|c|}
\hline \multicolumn{8}{|c|}{ Highest audible EBC frequency $(\mathrm{KHz})$} \\
\hline \multirow{2}{*}{\multicolumn{2}{|c|}{$\begin{array}{l}\text { Ten-year } \\
\text { Age Group }\end{array}$}} & \multirow[t]{2}{*}{$\mathbf{n}$} & \multirow[t]{2}{*}{ Median } & \multirow[t]{2}{*}{ Mean } & \multirow[t]{2}{*}{ St. Dev. } & \multicolumn{2}{|c|}{ Range } \\
\hline & & & & & & Min. & Max. \\
\hline 1 & $1-10$ уг & 1 & 18,40 & 18,40 & $*$ & 18,40 & 18,40 \\
\hline 2 & $11-20 \mathrm{yr}$ & 9 & 16,60 & 16,67 & 1,17 & 15,50 & 18,20 \\
\hline 3 & $21-30$ yr & 50 & 16,00 & 15,78 & 2,23 & 13,55 & 19,40 \\
\hline 4 & $31-40$ yr & 42 & 14,50 & 14,21 & 1,84 & 12,37 & 17,40 \\
\hline 5 & $41-50$ yr & 34 & 13,60 & 12,90 & 1,88 & 11,02 & 17,20 \\
\hline 6 & $51-60$ yг & 9 & 11,00 & 11,36 & 1,71 & 9,65 & 13,80 \\
\hline 7 & $61-70 \mathrm{yr}$ & 4 & 11,00 & 11,15 & 1,04 & 10,11 & 12,40 \\
\hline 8 & $71-80 \mathrm{yr}$ & $\mathbf{1}$ & 16,40 & 16,40 & $*$ & 16,40 & 16,40 \\
\hline
\end{tabular}


depicted in Fig. 2. Despite this drawback, the data would result in a more clearly defined and perhaps more usable tentative norm for clinical use. Follow-up studies utilizing much larger groups of subjects may result in the formulation of much tighter norms. Until then, using a baseline EBC audiogram against which any later audiograms can be compared, seems to be the better option.

The major advantage appears to be that this method of testing, i.e., determining only the highest audible EBC frequency, is a quick and easy one to apply, as only one parameter, that of highest audible frequency at maximum stimulation intensity, needs to be examined in each patient. There could therefore be the opportunity for excellent applications in high frequency hearing screening and quick monitoring of the early effects of ototoxic drugs and perhaps also the early detection of noise induced hearing loss.

The major obstacle still remains the fact that EBC thresholds reflect the hearing of both ears simultaneously, as there is as yet no reliable method of masking available on $\mathrm{EBC}$ audiometers. In ototoxicity monitoring, however, it would be a lesser problem as ototoxic drugs usually affect both ears equally and simultaneously.

\section{CONCLUSION}

We have managed to establish some kind of tentative norms for age-related bilateral highest frequency EBC hearing. It is also suggested that this quick and easy method of measuring the highest audible EBC frequency be used for screening purposes and possibly also for ototoxic and noise damage monitoring.

A larger study on a representative group of subjects may provide a much tighter set of norms and if a reliable method of masking EBC could be found, clinical norms for unilateral highest audible EBC hearing could then also be established. Until then, using a baseline EBC audiogram against which any later audiograms can be compared, seems to be the better option for clinical use.

\section{REFERENCES}

Corliss, L.M., Doster, M.E., Simonton, J. \& Downs, M.P. (1970). High frequency and regular audiometry among selected groups of high school students. J. Sch. Health, 40, 400-404.

Dadson, R.S. \& King, J.H. (1952). A determination of the normal threshold of hearing and its relation to the standardization of audiometers. J. Laryngol. Otol., 66, 366-378.

Fletcher, H. (1929). Speech and Hearing. Van Nostrand, New York.

Fletcher, J.L., Cairns, A. B., Collins, F.G. \& Endicott, J. (1967). High frequency hearing following meningitis. J. Aud. Res., 7, 223-227.

Frank, T. (1990). High-frequency hearing thresholds in young adults using a commercially available audiometer. Ear Hear, 11(8), 450 454.

Frank, T. \& Dreisbach, L.E. (1991). Repeatability of high frequency thresholds. Ear Hear, 12(4), 294-295.

Galton, F. (1876). Whistles for Determining the Upper Limit of Audible Sound in Different Persons. South Kensington Museum Conferences.

Harris, J.D. \& Myers, C.K. (1971). Tentative audiometric threshold levels standards from 8 to $18 \mathrm{KHz}$. J. Acoust. Soc. Am., 49,600 601.

Jacobson, E.J., Downs, M.P. \& Fletcher, J.L. (1969). Clinical findings in high frequency thresholds during known ototoxic drug usage. J. Aud. Res., 9, 379-385.

Northern, J.L., Downs, M.P., Rudmose, W., Glorig, A. \& Fletcher J.L. (1972). Recommended high-frequency audiometric threshold levels. J. Acoust. Soc. Am. 52(2), 585-595.

Okstad, S., Laukli, E. \& Mair, I.W.S. (1988). High frequency audiometry: Comparison of electric bone-conduction and airconduction thresholds. Audiology, 27, 17-26.

Rosen, S. \& Olin P. (1968). Hearing loss and coronary heart disease. Arch. Otolaryngol., 88, 251-253.

Rudmose, W. (1961). The Suprahigh-frequency Audiometer. TRACOR, incorporated, Austin, Texas.

Schechter, A.M., Fausti, S.A, Rappaport, B.Z. \& Frey, R.H. (1986) Age categorization of high-frequency auditory threshold data. $J$. Acoust. Soc. Am., 79(3), 767-771.

Schuknecht, H.F. (1955). Presbycusis. Laryngoscope, 65, 402-419.

Sivian, L.J. \& White, S.D. (1933). On minimal audible sound fields. J. Acoust. Soc. Am., 44, 257.

Stelmachowicz, P.G., Beauchaine, KA., Kalberer, A. \& Jesteadt, W. (1989). Normative thresholds in the $8-$ to $20-\mathrm{KHz}$ range as a function of age. J. Acoust. Soc. Am., 86(4), 1384-1391.

Teale, C., Goldman, J.M. \& Pearson, S.B. (1994). The association of age with the presentation and outcome of tuberculosis: a fiveyear survey. J.A.R.D., 6(4), 7-10.

Tonndorf, J. \& Kurman, B. (1984). High frequency audiometry. Ann. Otol. Rhinol. Laryngol., 93, 576-582.

Zislis, T \& Fletcher, J.L. (1966). Relation of high frequency thresholds to age and sex. J. Aud. Res., 6, 189-198. 